\title{
The rewards of science extend far beyond publication
}

\section{Good research and wise mentorship should be valued more highly than a name added to a paper.}

Sir - Peter A. Lawrence, in his

Commentary article "Rank injustice" (Nature 415, 835-836; 2002), describes ways in which senior scientists routinely abuse and exploit their juniors. My own experience is very different.

When I was a graduate student and postdoc, my mentors spent countless hours discussing science, experiments and data with me. When they gave seminars, my mentors advertised my work and acknowledged my contributions with every slide. As a result of all their guidance, I have been fortunate enough to have obtained my own lab, to have thrived in it, and to now have the great honour and pleasure of training young scientists myself. In short, good mentors spend time training their students, credit them fairly for their work, and guide them to independence; bad mentors do not.
Young scientists would be well advised to seek out good mentors. Our training system may not be perfect, but when I look around my department and university, I see that quality mentorship is unfailingly taken as seriously as is doing good science. For Lawrence to claim that mentors are routinely abusing young scientists is as irresponsible as it is cynical. More than obtaining fair "allocation of credit", the reward of doing good science includes learning about nature, helping other people and solving mysteries.

How do I rate other scientists? I don't count their Nature papers but rather how many of their students do well in their own labs. Now that's success!

Ben A. Barres

Department of Neurobiology,

Stanford University School of Medicine,

Stanford, California 94305-5125, USA required before anyone gets to be a principal investigator (PI), during which time the researcher has built up a corpus of knowledge and experience that benefits the younger scientists who come to work under his or her supervision.

Even if the PI is not the "discoverer" in a given instance, it is the PI who has created the circumstances in which the discovery was made. The PI deserves credit for qualifying herself or himself to head a laboratory, selecting the problem, getting the funding, recruiting younger colleagues and contributing to the work in various direct and indirect ways.

Rather than taking tennis rankings as a model to avoid, why not take a leaf out of the film industry's book? After every film, the credits not only name contributors but also say what they did (director, scriptwriter and so on). A scientific paper could list which co-authors carried out the critical experiments, which did the critical analyses and which 'just' arranged the funding.

Robert P. Bywater

Novo Nordisk A/S, Novo Nordisk Park, DK-2760 Måløv, Denmark

Dr Bywater's proposal has been Nature's policy since 1999, as outlined in two Opinion articles (Nature 415, 819; 2002 and Nature 399, 393; 1999). Nature encourages co-authors to specify the contribution they made to the paper in the acknowledgements section.

These letters are a small selection of the many that Nature and Dr Lawrence have received about his Commentary. The overwhelming majority were in support of his views. - Editor, Correspondence.

\section{Arab science is not stifled by censorship}

Sir - Including my photograph in the box "Science veiled in secrecy" on page 122 of your News Feature on Arab science "Blooms in the desert" (Nature 416, 120-122; 2002) — might suggest to your readers that I support the views expressed in the article, about censorship and secrecy in Arab countries.

In fact, I emphatically do not share any of these views. Given the level of cooperation between our organization and all leading Arab science and technology institutions, I do not wish in any way to be associated with statements such as those made in this box.

\section{Omar Bizri}

Chief, Technology Section, United Nations Economic and Social Commission for Western Asia, Beirut, Lebanon
Sir - It is always a pleasure to read one of Peter Lawrence's polemics ${ }^{1}$. On this occasion he is, of course, correct. Honorary
Sir - Few would dispute that the authorship system we have today is open to abuse and probably is frequently abused, as described by Peter Lawrence in his Commentary article (Nature 415, 835-836; 2002). Nevertheless, a long, successful stint in research laboratories is 